\title{
Model Analysis Android App
}

\author{
Vikrant V. Jadhav ${ }^{1}$, Meenakshi M. Tiwari², Ranjit Kamble³, Vasudevan S. D. ${ }^{4}$, Pallavi Daigavane ${ }^{5}$ \\ 1,2,3,4,5 Department of Orthodontics and Dentofacial Orthopaedics, \\ Sharad Pawar Dental College and Hospital, Sawangi, Wardha, Maharashtra, India.
}

Study models which are collected before starting orthodontic treatment are essential diagnostic aids. These models offer a 3-D view i.e. transverse, vertical and sagittal plane of both the arches. Model analysis includes the study of the both the arches in non-appearance of patient. Model analysis is an important tool in the diagnosis and treatment planning before, during and after treatment. It is essential to measure the total amount of crowding, spacing, expansion etc. within the arches, for proper treatment planning. It also helps us for accurate bracket positioning.

For this we have developed an android mobile app to abridge the tiresome mathematical calculations required for study model analysis and proper bracket placement. This app is called Model Analysis App, which runs on Android-based smartphones (an iPhone app is planned). This Model Analysis App is available on Google Play Store (play.google.com / store). New version has been added by including formulas for missing teeth and MBT chart for bracket positioning.

The app provides quick and accurate mathematical calculations for

1. Bolton's ratio. ${ }^{1}$

2. Bolton's ratio for Vidarbha population (SM ratio). ${ }^{2}$

3. Modified Bolton's ratio (ViVan ratio). ${ }^{3}$

4. Carey's Analysis.

5. Ashley Howe's Analysis.

6. Pont's Analysis.

7. Tanaka Johnston.

8. Peck and Peck index.

9. Formula for missing Maxillary Central and Lateral Incisor (ViVan Formula).

10. Formula for missing Maxillary and Mandibular Canine (VM Formula).

11. Formula for missing Mandibular molars (MeeVik Formula).

12. Formula for missing Mandibular Central Incisors (SV Formula).

13. MBT bonding guide.

This app is an excellent reference to these analyses and bracket placement.4,5
Corresponding Author: Dr. Vikrant V. Jadhav, $J R$ 3, Department of Orthodontics and Dentofacial Orthopedics, SPDC, Sawangi, Wardha, Maharashtra, India.

E-mail:vikrantjadhav9405@gmail.com

DOI: $10.14260 / \mathrm{jemds} / 2020 / 839$

How to Cite This Article: Jadhav VV, Tiwari MM, Kamble $R$, et al. Model analysis android app. J Evolution Med Dent Sci 2020;9(50):3825-3827, DOI: $10.14260 / j e m d s / 2020 / 839$

Submission 14-05-2020,

Peer Review 26-10-2020,

Acceptance 03-11-2020,

Published 14-12-2020.

Copyright (C) 2020 Vikrant V. Jadhav et al. This is an open access article distributed under Creative Commons Attribution License [Attribution 4.0 International (CC BY 4.0)]

\section{Using the App}

Indicators on the Model Analysis app's home screen are used for steering (Fig. 1). Snapping on the first row which is "Tooth Dimensions", will allow us to enter the mesiodistal widths of the permanent teeth in quadrant wise manner. (Fig. 2). These values can be changed by clicking the reverse arrow button. The "Reset" key will erase all values. References are available via the "help" button on each analysis screen. 


\section{Model Analysis}

Tooth Dimension

Tooth Dimension

Bolton

Upper and lower Teeth proportion

Bolton Vidarbha

Upper and lower Teeth proportion

Modified Bolton Vidarbha

Upper and lower Teeth proportion

Arch Perimeter Analysis

Upper TSALD

Carey's Analysis

lower TSALD

Ashley Howe's Analysis

Need for Expansion / Extraction

Pont's Analysis

Ideal Arch Width

Tanaka Johnston

Predict Cuspid + Bicuspid width

Peck and Peck Index

Measure the Mesiodistal width of lower Incisors

\section{Figure 1. Model Analysis App Home Screen}

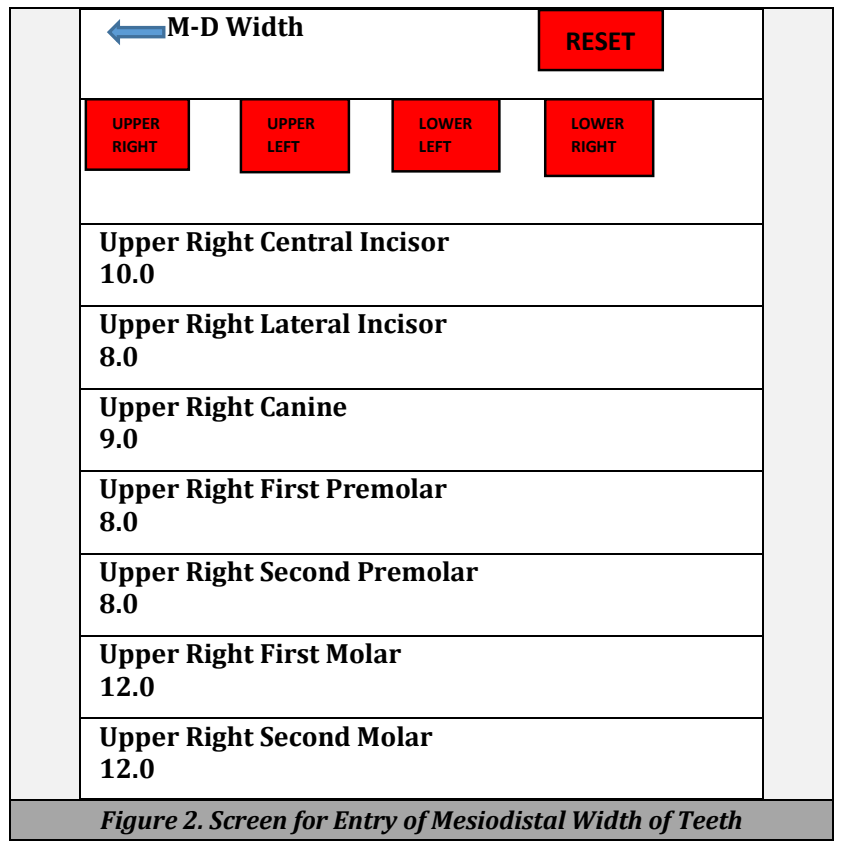

\begin{tabular}{|c|}
\hline Bolton \\
Overall Ratio \\
$94.0 \%$ \\
\hline $\begin{array}{c}\text { Overall Mandibular Excess } \\
5.0 \mathrm{~mm}\end{array}$ \\
Anterior ratio \\
$\mathbf{7 7 . 2} \%$ \\
Anterior Mandibular Excess \\
2 mm \\
Dimensions \\
\hline Sum of maxillary 12 $=104$ \\
Sum of Mandibular 12 $=98$ \\
Sum of maxillary $6=32$ \\
Sum of Mandibular $6=25$ \\
\\
\hline Figure 3. Bolton's Ratio \\
\hline
\end{tabular}

$\Longleftarrow$ Vertical Dimensions

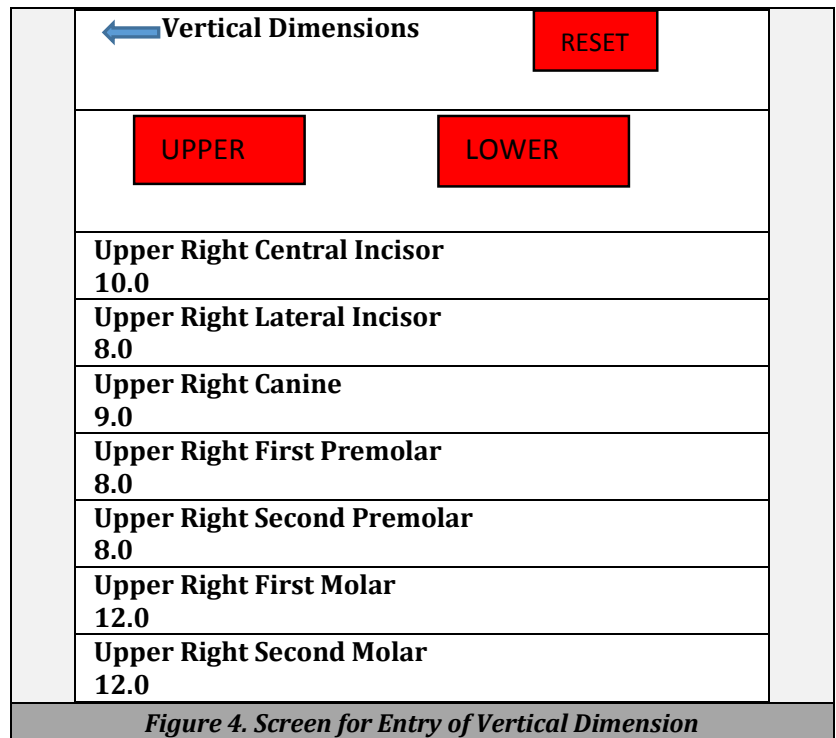

\begin{tabular}{|l|l|}
\hline \multicolumn{1}{|c|}{ Bolton } & HELP \\
\hline $\begin{array}{l}\text { Overall Ratio } \\
94.0 \%\end{array}$ \\
\hline $\begin{array}{l}\text { Overall Mandibular Excess } \\
5.0 \mathrm{~mm}\end{array}$ \\
\hline $\begin{array}{l}\text { Anterior ratio } \\
77.2 \%\end{array}$ \\
\hline $\begin{array}{l}\text { Anterior Mandibular Excess } \\
2 \mathrm{~mm}\end{array}$ \\
\hline $\begin{array}{l}\text { Dimensions } \\
\text { Sum of maxillary } 14=104 \\
\text { Sum of Mandibular } 14=98 \\
\text { Sum of maxillary } 6=32 \\
\text { Sum of Mandibular } 6=25\end{array}$ \\
\hline \multicolumn{1}{|c|}{ Figure 5. Modified Bolton's Ratio Analysis } \\
\hline
\end{tabular}

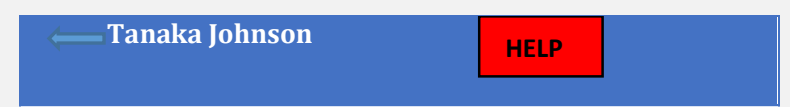

\section{Expected width of Upper $3+4+5$}

25 mm

Expected width of Lower $3+4+5$

$24 \mathrm{~mm}$

Sum of lower Incisors

24

Half of Sum of Lower Incisor

12

Figure 6. Tanaka Johnston Analysis

\section{Conclusions}

All other analyses are available at android app at play store by name "Model Analysis App".

This app is used for diagnosis and treatment planning. It will be streamlined and organized for orthodontists in the near future.

Financial or other competing interests: None.

Disclosure forms provided by the authors are available with the full text of this article at jemds.com. 


\section{REFERENCES}

[1] Tonn P. Über die mesio-distalen Zahnbreitenrelationen der Zähne des Oberkiefers zu den entsprechenden des Unterkiefers bei normaler und anormaler Okklusion [Med Diss]. Berlin 1937.

[2] Bolton WA. Disharmony in tooth size and its relation to the analysis and treatment of malocclusion. Angle Orthod 1958;28(3):113-30.
[3] McLaughlin RP, Bennet JC. Orthodontic treatment mechanics and the preadjusted appliance. London: Wolfe Medical Publishing 1993.

[4] Jindal R, Bunger E. Bolton's intermaxillary tooth size ratios among school going children in Punjab population. Indian Journal of Oral Sciences 2013;4(3):110.

[5] Subbarao VV, Regalla RR, Santi V, et al. Interarch tooth size relationship of Indian population: does Bolton's analysis apply? J Contemp Dent Pract 2014;15(1):103-7. 